\title{
Heterotrimeric $\mathrm{G}$ protein are involved in the regulation of multiple agronomic traits and stress tolerance in rice
}

\author{
Yue Cui ${ }^{1 \dagger}$, Nan Jiang ${ }^{2+}$, Zhengjin $\mathrm{Xu}^{1}$ and Quan $\mathrm{Xu}^{{ }^{*}}$
}

\begin{abstract}
Background: The heterotrimeric $G$ protein complex, consisting of $G a, G \beta$, and $G y$ subunits, are conserved signal transduction mechanism in eukaryotes. Recent molecular researches had demonstrated that $G$ protein signaling participates in the regulation of yield related traits. However, the effects of $\mathrm{G}$ protein genes on yield components and stress tolerance are not well characterized.

Results: In this study, we generated heterotrimeric G protein mutants in rice using CRISPR/Cas9 (Clustered Regularly Interspaced Short Palindromic Repeats) gene-editing technology. The effects of heterotrimeric G proteins on the regulation of yield components and stress tolerance were investigated. The mutants of gs 3 and dep 1 generated preferable agronomic traits compared to the wild-type, whereas the mutants of rgal showed an extreme dwarf phenotype, which led to a dramatic decrease in grain production. The mutants showed improved stress tolerance, especially under salinity treatment. We found four putative extra-large G proteins (PXLG) 1-4 that also participate in the regulation of yield components and stress tolerance. A yeast two hybrid showed that the RGB1 might interact with PXLG2 but not with PXLG1, PXLG3 or PXLG4.
\end{abstract}

Conclusion: These findings will not only improve our understanding of the repertoire of heterotrimeric $\mathrm{G}$ proteins in rice but also contribute to the application of heterotrimeric G proteins in rice breeding.

Keywords: Rice, Heterotrimeric G protein, CRISPR/Cas9, Yield components, Stress tolerance

\section{Background}

Much of the seminal work on heterotrimeric G proteins was accomplished over the past 40 years, and thus it is no wonder that this pathway is the best understood in the world. The heterotrimeric G proteins, comprising $\alpha$, $\beta$, and $\gamma$ subunits, perceive extracellular stimuli through cell surface receptors, and then transmit signals to effectors to initiate numerous cellular behaviors [1]. These include responses to hormones, drought, and pathogens, and developmental events such as lateral root formation, hypocotyl elongation, hook opening, leaf expansion, and silique development [2]. A large heterotrimeric $G$ protein family exists in the mammalian genome, for example, the human genome encodes $23 \mathrm{G} \alpha, 5 \mathrm{G} \beta$, and 12

\footnotetext{
* Correspondence: kobexu34@syau.edu.cn

†Yue Cui and Nan Jiang contributed equally to this work.

${ }^{1}$ Rice Research Institute of Shenyang Agricultural University, Shenyang

110866, China

Full list of author information is available at the end of the article
}

$\mathrm{G \gamma}[3,4]$, whereas the heterotrimeric $\mathrm{G}$ protein repertoire in plants is much simpler than in animals [5]. In the rice genome, there are single-copy of canonical $G \alpha$ (RGA1) and $\mathrm{G} \beta(R G B 1)$ subunits [6, 7], and two canonical Gy subunits (RGG1 and RGG2) [8]. Recent molecular studies have found that there are three unusually large proteins with sequences similar to $G \alpha$ subunits in the genome of Arabidopsis, these are named extra-large GTP-binding proteins, or XLGs [9]. The XLGs have a long cys-rich domain in the $\mathrm{N}$-terminal compared to the canonical $G \alpha$, and all three XLGs of the $G \alpha$ subunit show GTP-binding and GTPase activity [10, 11]. Similarly, there are three non-canonical Gy subunits, GS3, $D E P 1$, and $G G C 2$ in the rice genome [12]. The noncanonical $\mathrm{G} \gamma$ subunits also have a long cys-rich domain in the C-terminal compared to RGG1 and RGG2 [13$15]$. Interestingly, the variation in the cys-rich domain contributes to the improvement of important agronomic traits. The varieties harboring different GS3 alleles 
generated diversity in grain sizes [16, 17], and a deletion of the cys-rich domain of the dep1-1 allele resulted in a dense and erect panicle architecture, and a significant increase of grain number per panicle [18-20]. Taken together, the heterotrimeric XLG proteins and noncanonical Gy subunits that do not exist in the repertoire of heterotrimeric $G$ proteins in animals might identify additional signal transduction pathways and expand the repertoire of heterotrimeric $\mathrm{G}$ proteins.

CRISPR/Cas9 systems have been successfully applied as efficient genome editing tools in a number of plant species [21-24]. The CRISPR/Cas9 gene-editing technology has been used to verify the function of important yield-related genes, such as DEP1, GS3, IPA1, and Gn1a [22]. In the present study, we generated one Go mutant, one $G \beta$ mutant, five $G \gamma$ mutants, and four extra-large Go mutants using CRISPR/Cas9 gene-editing technology. We assessed the yield components and stress tolerance of the mutants, revealing the distinctly different effects of the heterotrimeric $G$ protein mutants on yield components and stress tolerance. We aimed to gain insight into the heterotrimeric $G$ proteins in the rice genome, with the goal of providing better information and germplasm resources for rice breeding.

\section{Results}

Heterotrimeric $\mathrm{G}$ protein-encoding gene investigation of the transformation receipt

The japonica rice variety Sasanishiki was used as wild type (WT) for the transformation in this study. Sasanishiki is a typical Japanese japonica variety that was widely cultivated in Northeast China before the 1980s. Sasanishiki then became a major backbone parent, and many rice varieties in Northeast China share the genome segment from Sasanishiki. Sasanishiki thus represents an ideal receipt for transformation in this study, not only for the functional demonstration of heterotrimeric G protein-encoding genes in rice, but also for the genetic improvement by molecular breeding in Northeast China. Thus, we first assessed the heterotrimeric $G$ proteinencoding genes of Sasanishiki. The G $\alpha, G \beta$, and five $G \gamma$ genes of Sasanishiki were investigated (Table 1). The results showed that Sasanishiki shared the G protein genes to Nipponbare. No frame shift was detected between Nipponbare and Sasanishiki. Thus, we assumed that all seven $G$ protein genes in Sasanishiki were functional.

\section{Generation of heterotrimeric $\mathrm{G}$ protein mutants using CRISPR/Cas9}

In order to evaluate the effects of heterotrimeric G protein-encoding genes on rice agronomic traits, we used CRISPR/Cas9 to specifically induce mutagenesis of the $G$ protein. We sequenced 20 plants of each mutant to examine the mutation efficiency in the $\mathrm{T}_{0}$ generation. The result showed that mutations occurred in $64.29 \%$ of plants, and $10.71 \%$ of sequenced plants had a putative homozygous mutation (Fig. 1 and Table 2). Seven $\mathrm{T}_{1}$ lines with homozygous mutations and the WT were used in further analyses. At least two independent transgenic lines were obtained for each Heterotrimeric G protein encoding gene except for $r g g 2$ (Fig. 1). Forty $\mathrm{T}_{1}$ plants for each mutant and WT were sown in the experimental field of Shenyang Agricultural University $\left(\mathrm{N} 41^{\circ}, \mathrm{E} 123^{\circ}\right)$ on 23 April 2018. We recorded the heading time when the first panicle had emerged from the sheath. The results showed that the $r g b 1, r g g 1, \operatorname{rgg} 2, g s 3$, and dep 1 mutants underwent heading significantly earlier than the WT. The rgal and $g g c 2$ mutants showed a similar heading time as the WT (Fig. 2).

\section{The yield components of heterotrimeric $\mathrm{G}$ protein mutants}

The heterotrimeric $G$ protein is involved in the regulation of multiple agronomic traits, including grain size and panicle architecture. Thus, we compared the yield components of the seven $G$ protein mutants and the WT (Fig. 2). The results showed that the independent mutant lines exhibited similar phenotypic changes. The rgal showed a significant dwarf phenotype, with a dramatic decrease in panicle length, grain length, 1000 grain weight, and setting rate compared to that of the WT. The $r g b 1$ mutant exhibited a semi-dwarf phenotype, and the panicle number was less than that of the WT. Sun

Table 1 Details of the target genes modified in this study

\begin{tabular}{lllll}
\hline Heterotrimeric G protein & Gene & Locus & Function & Reference \\
\hline Ga & RGA1 & Os05g0333200 & F & ángel Ferrero-Serrano et al. (2016, 2018) [25, 26] \\
GB & RGB1 & Os03g0669200 & F & Zhang et al. (2015) [7]; Utsunomiya et al. (2011) [27] \\
GY & RGG1 & Os03g0635100 & F & Xu et al. (2016) [28] \\
& RGG2 & Os02g0137800 & F & Miao et al. (2019) [29] \\
& GS3 & Os03g0407400 & F & Mao et al. (2010) [30] \\
& GGC2 & Os08g0456600 & F & Xu et al. (2016) [28] \\
& DEP1 & Os09g0441900 & F & Huang et al. (2009) [18]; Wang et al. (2009) [20] \\
\hline
\end{tabular}




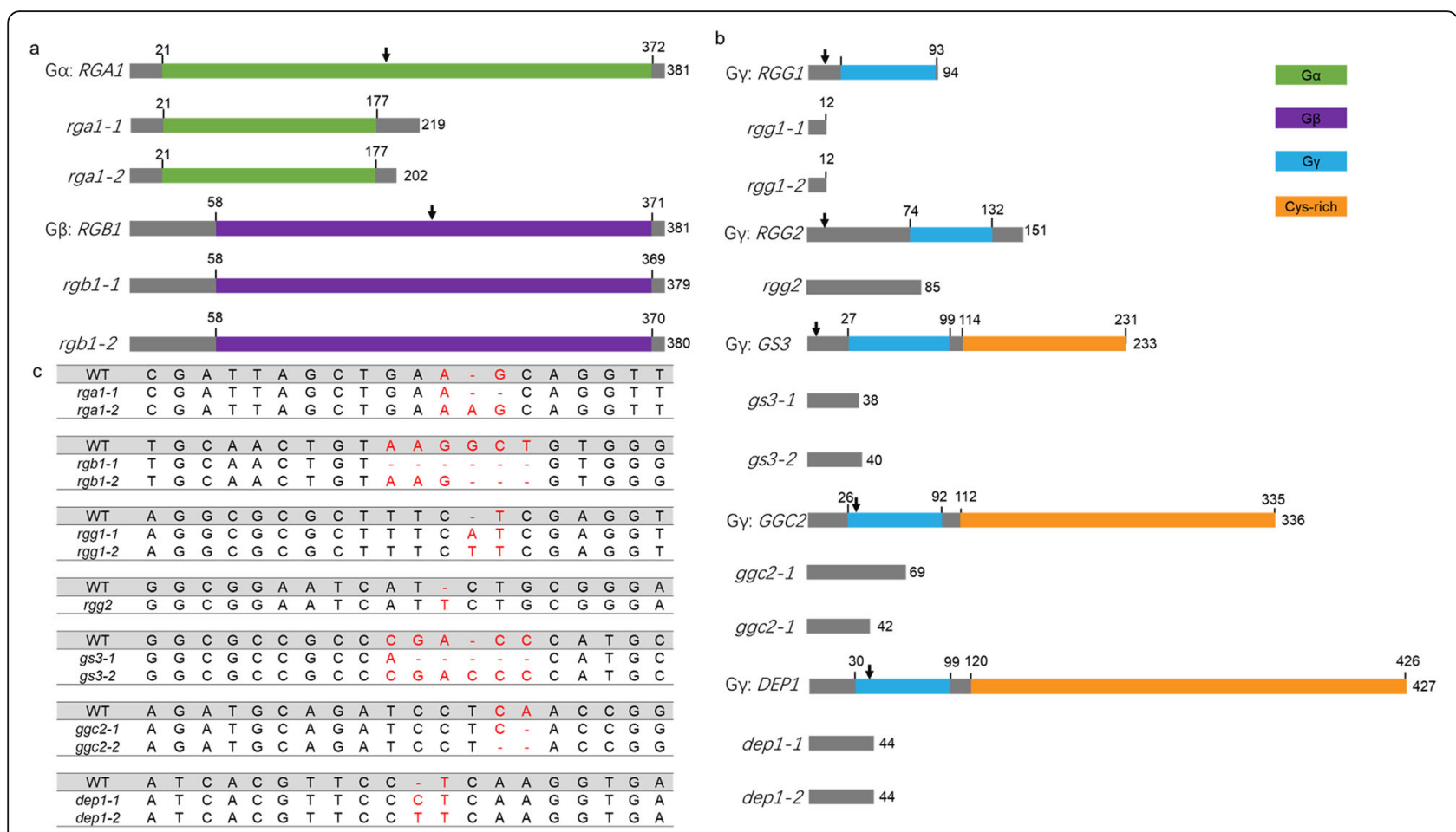

Fig. 1 The schematic representation of the heterotrimeric $G$ proteins and the sequences of the mutants generated by CRISPR/Cas 9 gene editing. a The schematic representation of the heterotrimeric $\mathrm{Ga}$ and $\mathrm{G} \beta$ proteins in rice. The functional domains are shown in different colors. The black arrow indicates the position of the sgRNA. The number indicates the amino acid sequence. $\mathbf{b}$ The protein schematic representation of the heterotrimeric Gy proteins in rice. The functional domains are shown in different colors. The black arrow indicates the position of the sgRNA. The number indicates the amino acid sequence. c The sequences of the heterotrimeric G protein mutants generated by CRISPR/Cas9 gene editing

et al. and Gao et al. reported that the null mutant of RGB1 generated by CRISPR/Cas9 gene editing technology was lethal $[31,32]$. However, the three base and six base deletions in rgb1-1 and $r g b 1-2$ did not cause a frame shift, which might be the reason for the survival of $r g b 1-1$ and $r g b 1-2$. In the Gy subunits, the $r g g 1 \mathrm{mu}-$ tant had longer but fewer panicles than that of the WT, and the rgg2 mutant showed a decrease in plant height compared to that of the WT. The ggc2 and dep1 mutants exhibited a decrease in plant height, and the dep 1 mutant had a shorter grain but a greater grain number per panicle compared to that of the WT. The gs3 mutant had a higher panicle number per plant and a longer grain length, which led to an increase in the 1000 grain weight compared to that of the WT.

\section{The stress tolerance of the heterotrimeric $\mathrm{G}$ protein mutants}

We then examined the drought, chilling, and salinity tolerance of the heterotrimeric $G$ protein mutants (Fig. 3). As the independent mutant lines exhibited similar phenotypic changes, we only used the number 1 transgenic line

Table 2 Percentage of T0 plants found with mutations in target gene

\begin{tabular}{|c|c|c|c|c|c|}
\hline \multirow{2}{*}{$\begin{array}{l}\text { Target } \\
\text { gene }\end{array}$} & \multirow{2}{*}{$\begin{array}{l}\text { No. of } \\
\text { plants } \\
\text { examined }\end{array}$} & \multicolumn{2}{|c|}{ Plants with mutations } & \multicolumn{2}{|c|}{ Putative homozugous mutations } \\
\hline & & Number & Mutation rate $(\%)$ & Number & Mutation rate (\%) \\
\hline RGA1 & 20 & 15 & 75.00 & 1 & 5.00 \\
\hline RGB1 & 20 & 13 & 65.00 & 0 & 0.00 \\
\hline RGG1 & 20 & 13 & 65.00 & 7 & 35.00 \\
\hline RGG2 & 20 & 14 & 70.00 & 4 & 20.00 \\
\hline GS3 & 20 & 18 & 90.00 & 1 & 5.00 \\
\hline GGC2 & 20 & 3 & 15.00 & 0 & 0.00 \\
\hline DEP1 & 20 & 14 & 70.00 & 2 & 10.00 \\
\hline Total & 140 & 90 & 64.29 & 15 & 10.71 \\
\hline
\end{tabular}




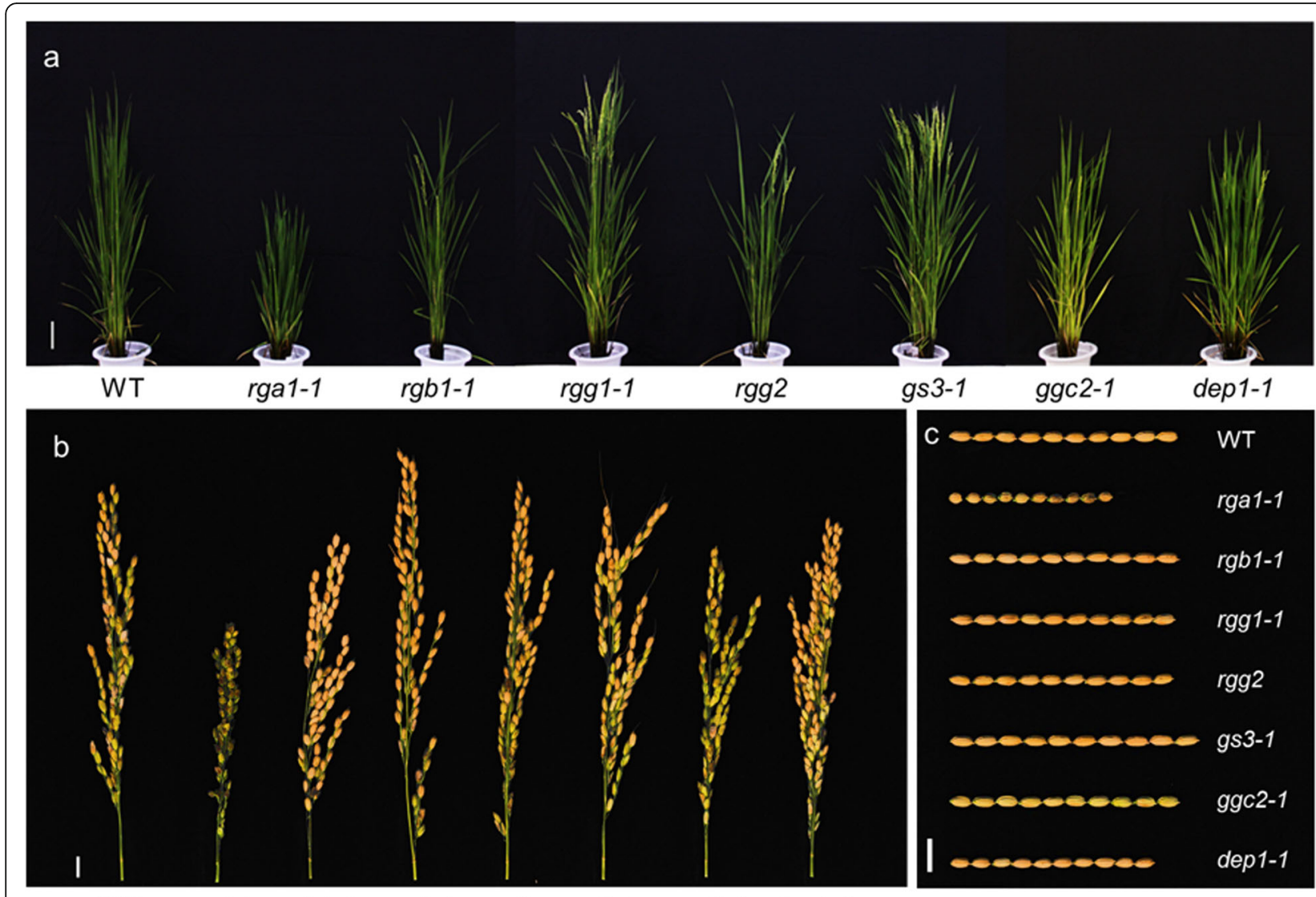

d

WT rga1-1 rgb1-1 rgg1-1 rgg2
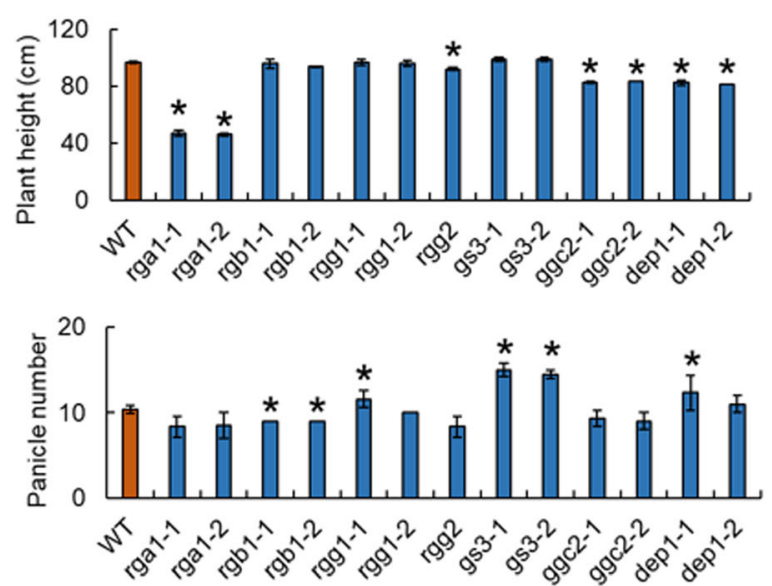

$\mathrm{h}$

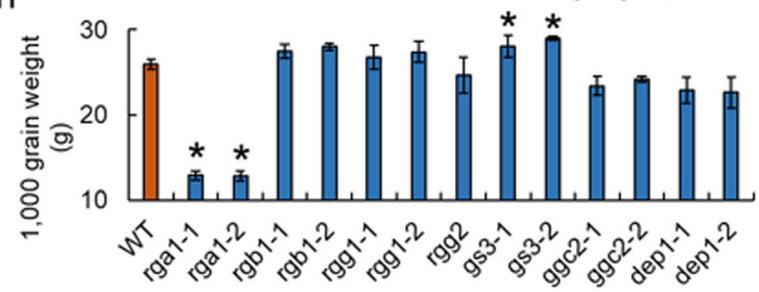

e

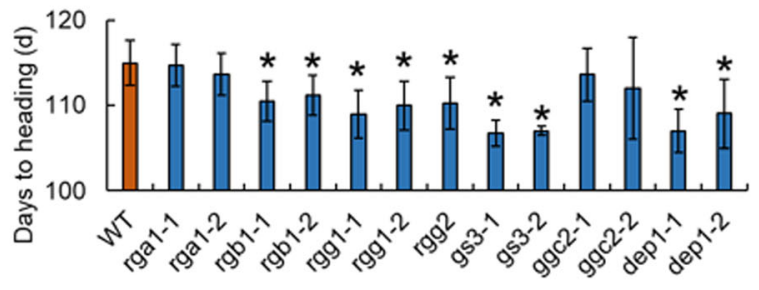

g
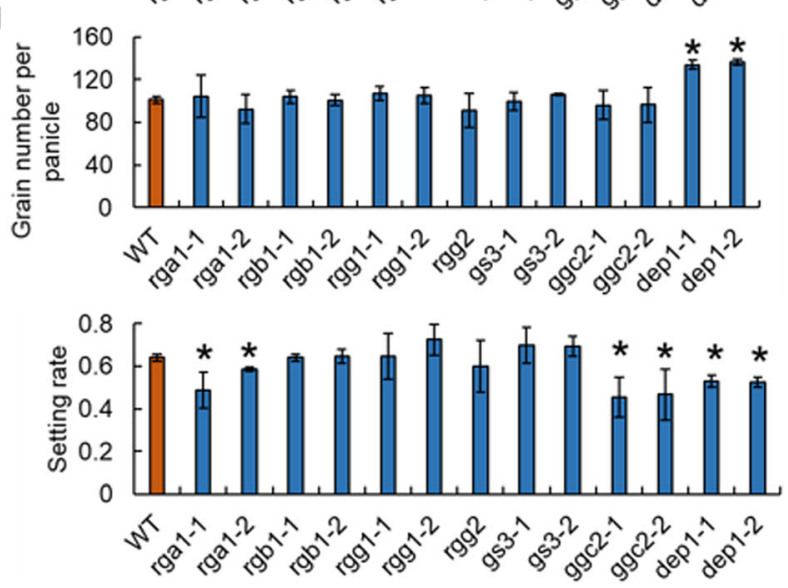

Fig. 2 Genetic effects of the heterotrimeric G protein on plant architecture, panicle size, grain size, and yield components. a The whole plants of the heterotrimeric $\mathrm{G}$ protein mutants. Bar $=10 \mathrm{~cm}(\mathbf{b})$ The panicle of the heterotrimeric $\mathrm{G}$ protein mutants. $\mathrm{Bar}=1 \mathrm{~cm}(\mathbf{c})$ The grains of the heterotrimeric $\mathrm{G}$ protein mutants. Bar $=1 \mathrm{~cm}(\mathbf{d}-\mathbf{i})$ The plant heights, heading times, panicle numbers, grain numbers per panicle, 1000-grain weight, and setting rates of the heterotrimeric G protein mutants. * indicates significance at the $5 \%$ level 


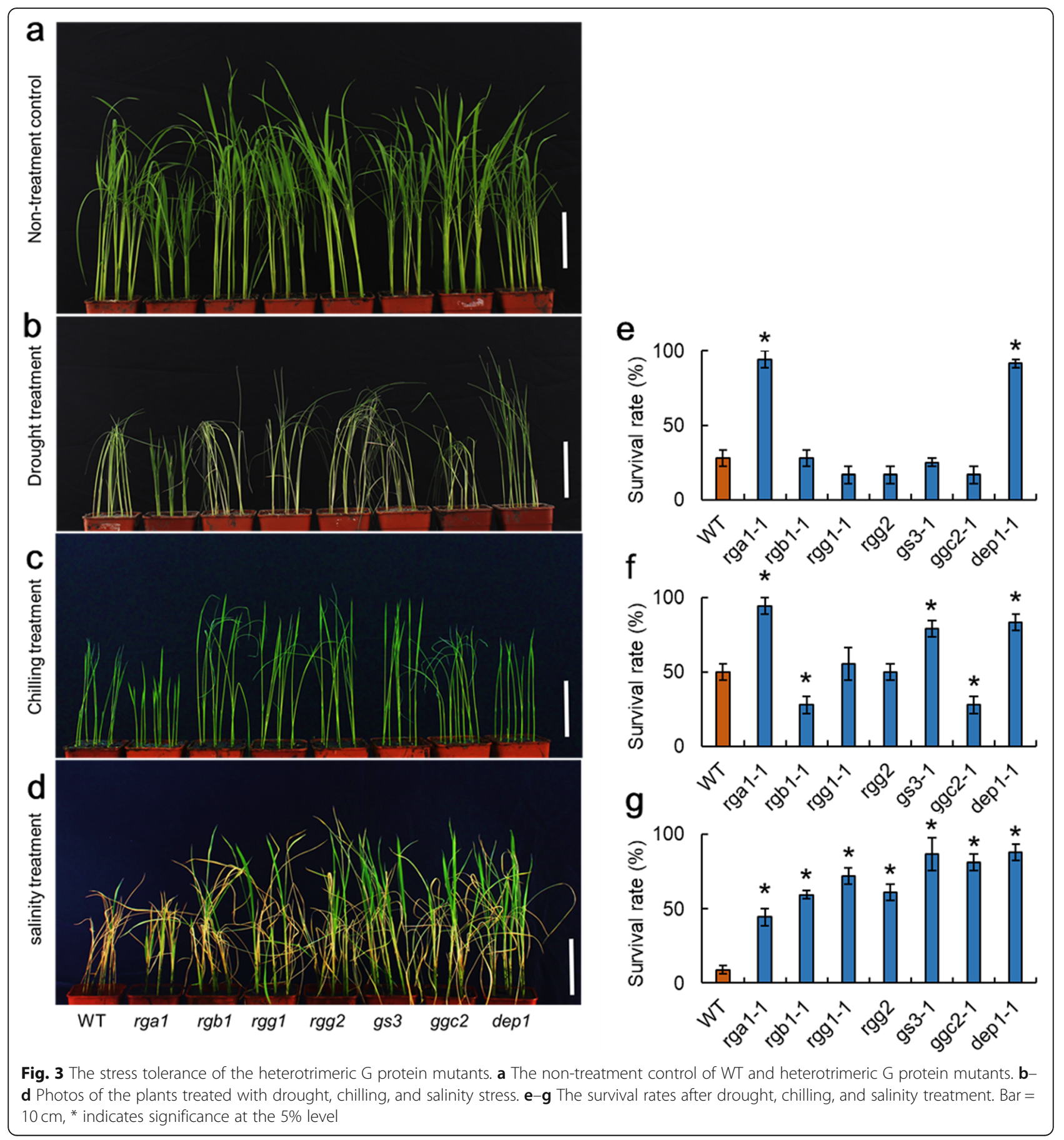

for each heterotrimeric $G$ protein for the stress tolerance survey. In the drought tolerance survey, the rga1 and dep1 mutants showed an enhanced drought tolerance compared to the WT, whereas the $r g b 1, r g g 1, r g g 2, g s 3$, and $g g c 2$ mutants exhibited similar deficiencies caused by drought. In the chilling treatment test, the $r g b 1$ and $g g c 2$ mutants were more sensitive than the WT. The rgal and dep1 mutants showed improved chilling tolerance compared to the WT. In the salinity treatments, all of the heterotrimeric mutants showed enhanced salinity tolerance compared to the WT, especially the $g_{s} 3$ and dep1 mutants. Taken together, these results suggest that the heterotrimeric $G$ protein might participate in multiple stress response mechanisms.

\section{The extra-large Ga protein in rice}

The bioinformatics analysis showed that there were four putative extra-large $G \alpha$ protein (pxlg1-4) encoding 
genes in the genome of rice (Table 3). We then generated mutants of four pxlg genes (Fig. 4). The four pxlg mutants showed an early flowering phenotype compared to the WT (Fig. 5). The plxg1 mutant had a shorter panicle but a longer grain than that of the WT. The panicle number of $p x \lg 1$ was significantly increased compared to that of the WT. The settings rate of $p x \lg 2$ and $p x \lg 3$ were decreased compared to that of the WT. The pxlg1 had a longer grain length than that of the WT, that led to an increase in 1000 grain weight. The two independent transgenic lines of $p x \lg 2$ showed slight differences in 1000 grain weight, the $p x \lg 2-1$ showed significantly decrease in 1000 grain weight, whereas the $p x \lg 2-2$ had a similar 1000 grain weight compared to the WT. We also investigated the stress tolerance of the four pxlg mutants (Fig. 6). In the drought treatment, pxlg4 showed enhanced drought tolerance compared to the WT and the other three pxlgs. In the chilling treatment, $p x \lg 4$ exhibited improved chilling tolerance compared to the WT. In the salinity treatment, all four pxlgs showed enhanced salinity tolerance, particularly $p x \lg 3$ and $p x \lg 4$, which had greater chilling tolerance than that of WT, pxlg1, and $p x \lg 2$. We subsequently surveyed whether the PXLGs interacted with RGB1 in rice using a yeast two hybrid analysis. The results showed that RGB1 interacted with PXLG2, but not with PXLG1, PXLG3, or PXLG4 (Fig. 7).

\section{Discussion}

The heterotrimeric $G$ proteins participate in a number of biological processes. Previous studies have shown that heterotrimeric $G$ protein mutants exhibited various phenotypic changes. The null mutant of the RGA1 gene exhibits a severe dwarf phenotype in rice [33, 34], whereas the down-regulation of the expression of the RGA1 gene causes a semi-dwarf phenotype [19]. Microarray analysis of $R G A 1$ showed that $R G A 1$ might participate in the regulation of multiple abiotic stresses, such as drought, salinity, heat, and cold tolerance [35]. During drought, rgal mutant plants exhibit greater stomatal conductance than the WT, but both genotypes exhibit the same transpirational water loss per unit leaf area
[25]. A recent study showed that $R G A 1$ could regulate photoprotection and photoavoidance in rice [26]. The COLD1 gene could regulate $\mathrm{G} \alpha$ to confer chilling tolerance in rice [36]. Our studies confirmed that the null mutants of RGA1 showed a severe dwarf phenotype and exhibited stress tolerance under drought, chilling, and salinity treatments. The suppression of $R G B 1$ causes dwarfism and browning of the internodes and lamina joint regions [27], and the null mutant of $R G B 1$ was lethal under the genetic background of ZH11 [31, 32]. Our study also showed that the mutation of $r g b 1$ caused a dwarfish plant architecture, with the panicle length being shorter than that of the WT. We concluded that rgb1-1 and rgb1-2 harbor mild alleles of RGB1 as the 3bp and 6-bp deletions did not cause frame shifts. Overexpression of $R G G 2$ in Nipponbare led to a reduced plant height and decreased grain size, whereas the mutants generated via CRISPR/Cas9 in the Zhenshan 97 background exhibited enhanced growth, including elongated internodes, increased 1000-grain weight and plant biomass, and enhanced grain yield per plant [29]. However, the rgg2 CRISPR/Cas9 gene-edited plants under the Sasanishiki genetic background showed a similar phenotype to that of WT (Fig. 2). Interestingly, the mutant of rgg1 showed enhanced growth, which was similar to the rgg2 mutants in the Zhenshan 97 genetic background (Fig. 2). These results demonstrate that both RGG1 and RGG2 might act as regulators of plant growth in rice. Recent molecular studies identified two noncanonical Gy subunits DEP1 and GS3 as major quantitative trait loci (QTLs) [28]. Several studies identified the GS3 locus as a major QTL for grain length, grain width, and grain weight, and DEP1 corresponded to the dense erect panicle and increased grain number [18, 30, 37]. Our study showed that the knock-out mutation of $g_{s} 3$ could significantly increase the grain length compared to that of the WT, whereas the knock-out mutant of dep1 showed significantly decreased grain length. The dep1 mutants had a shorter panicle than the WT but exhibited a significant increase in grain number per panicle. The mutants of another atypical $\mathrm{Gr}$ protein gene, $G G C 2$, did not exhibit a preferential phenotype as

Table 3 Percentage of T0 plants found with mutations in target gene

\begin{tabular}{|c|c|c|c|c|c|c|c|}
\hline \multirow{2}{*}{$\begin{array}{l}\text { Putative } \\
\text { extra- } \\
\text { large G } \\
\text { protein }\end{array}$} & \multirow[t]{2}{*}{ Locus } & \multirow[t]{2}{*}{ Function } & \multirow{2}{*}{$\begin{array}{l}\text { No. of } \\
\text { plants } \\
\text { examined }\end{array}$} & \multicolumn{2}{|c|}{ Plants with mutations } & \multicolumn{2}{|c|}{ Putative homozugous mutations } \\
\hline & & & & Number & Mutation rate (\%) & Number & Mutation rate (\%) \\
\hline pxlg1 & Os06g0111400 & $\mathrm{F}$ & 20 & 12 & 60.00 & 4 & 20.00 \\
\hline pxlg2 & Os11g0206700 & $\mathrm{F}$ & 20 & 11 & 55.00 & 2 & 10.00 \\
\hline pxlg3 & Os12g0593000 & $\mathrm{F}$ & 20 & 10 & 50.00 & 1 & 5.00 \\
\hline pxlg4 & Os10g0117800 & $\mathrm{F}$ & 20 & 11 & 55.00 & 1 & 5.00 \\
\hline Total & & & 80 & 44 & 55.00 & 8 & 10.00 \\
\hline
\end{tabular}

F represents functional alleles 


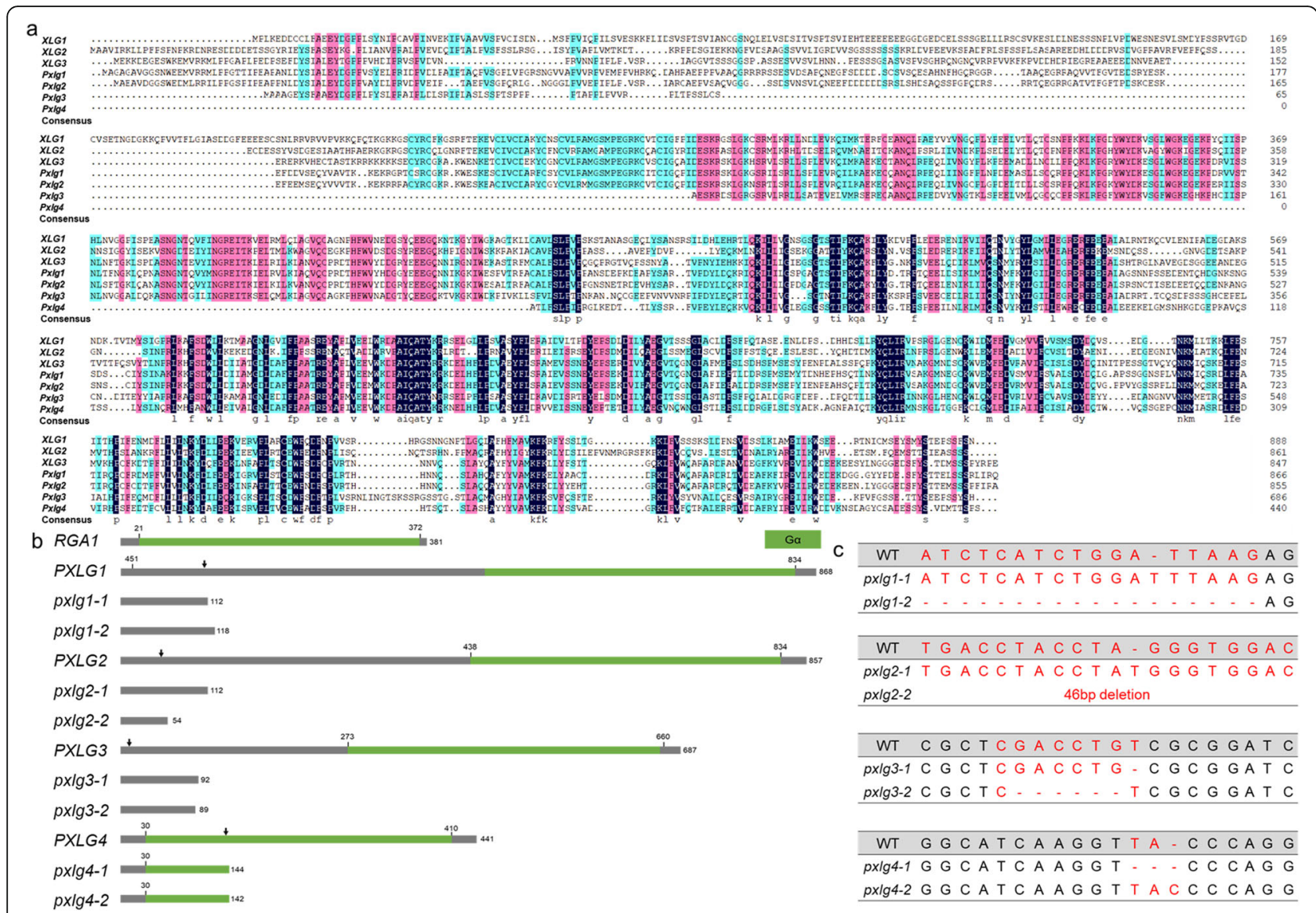

Fig. 4 The putative extra-large Ga protein in rice. a A phylogenetic analysis of the extra-large G protein in Arabidopsis and rice, in which identical and conserved residues are indicated by different colors. $\mathbf{b}$ The schematic representation of the putative extra-large Ga protein in rice. The black arrow indicates the position of the sgRNA. c The sequence of the putative extra-large Ga protein mutant generated by CRISPR/Cas9 gene editing

observed in the gs 3 and dep1 mutants. The panicle size and setting rate were penalized in the ggc2 mutant. Our study also indicated that the $r g b 1, r g g 1, r g g 2, g s 3$ and dep1 mutants underwent heading significantly earlier than the WT, results that had not been reported in previous studies. The early heading phenotype observed in the present study indicated that the $G$ protein signaling might participate in the control network of plant heading.

Recently, a "self-inhibition" model was constructed to explain the gain of function mutants of dep1 and gs3. The hypothesis is that the C-terminal domains inhibited the $\mathrm{N}$-terminal domains in non-canonical $\mathrm{Gr}$ proteins $[12,30]$. Although both C-terminal and N-terminal regions is thought to be involved in protein interaction, the molecular mechanisms of the observed selfinhibition of GS3 and DEP1 remain elusive [19, 30]. As $D E P 1$ plays a crucial role in the understanding of $\mathrm{G}$ protein in rice and in rice breeding, a number of studies employing CRISPR/Cas9 technology have been conducted to verified the function of DEP1 [22, 31, 38-41]. The DEP1 CRISPR/Cas9 gene-edited plants with an eliminated C-terminal exhibited an increase in grain number per panicle, reductions in plant height, panicle length, and grain length, and an erect panicle architecture, whereas the plants that had lost both the Gy and cys-rich domains showed reductions in setting rate and grain number per panicle. Additionally, we noticed the truncated dep1 with an eliminated C-terminal also exhibited a reduction in grain number per panicle under the genetic background of Nongken 57 and Wuyunjing $8[42,43]$. These results suggested the truncated dep 1 alleles could generate opposite effects to grain number per panicle under different genetic background. The present study showed that the mutants with both the Gy domain and cys-rich domains eliminated showed an increase in grain number per panicle (Fig. 2). Li et al. generated three lines harboring different length of truncation at $\mathrm{C}$ terminal of DEP1 using CRISPR/Cas9 gene editing technology, and the three lines exhibited similar phenotypic changes of the grain size [40]. Taken together, we hypothesized that both the two types of DEP1 alleles (the allele eliminated $\mathrm{G} \gamma$ and cys-rich domains, and allele eliminated only cys-rich domains) could increase the 

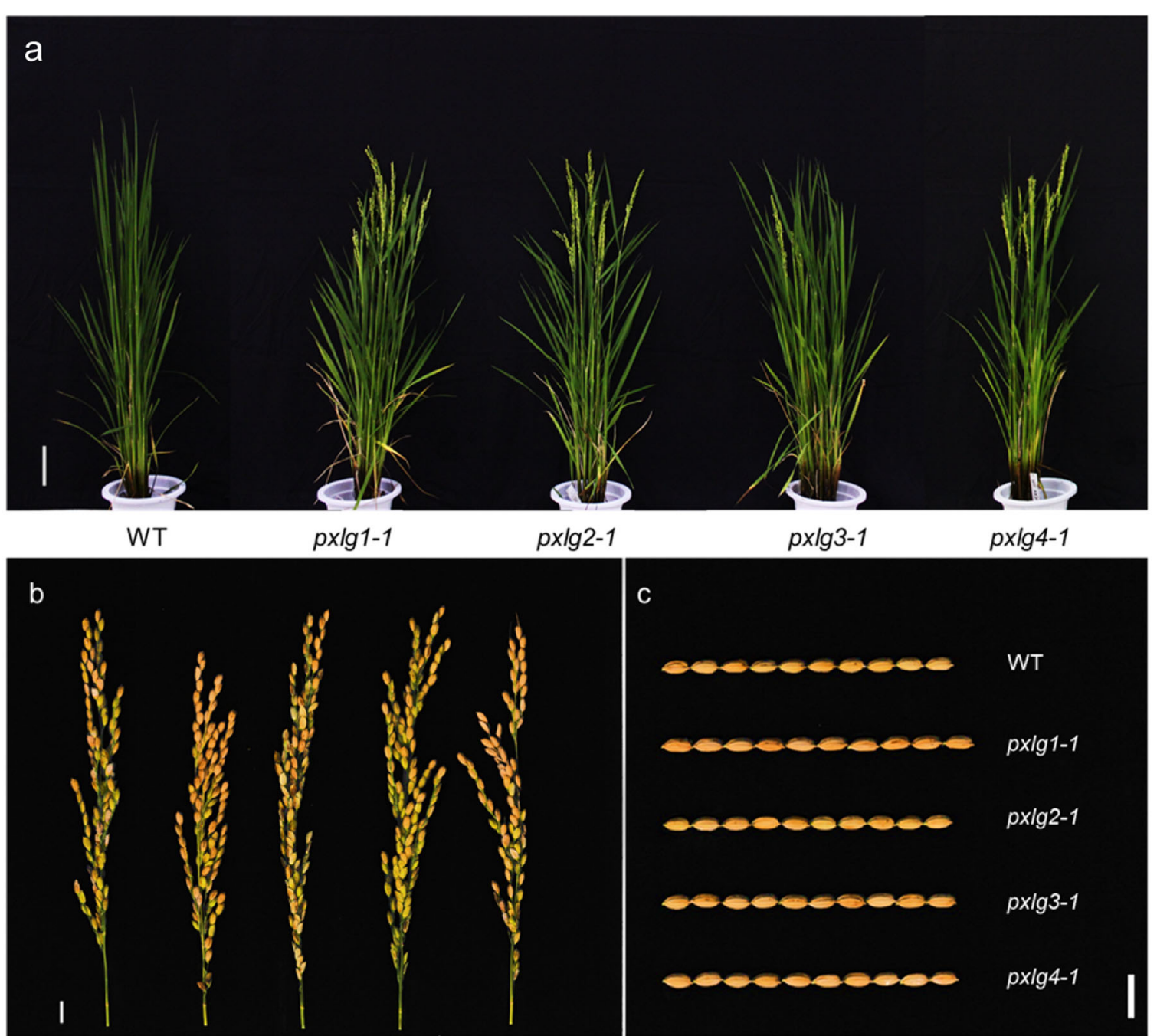

WT $p x \lg 1-1 \quad p x \lg 2-1 \quad p x \lg 3-1 \quad$ pxlg4-1
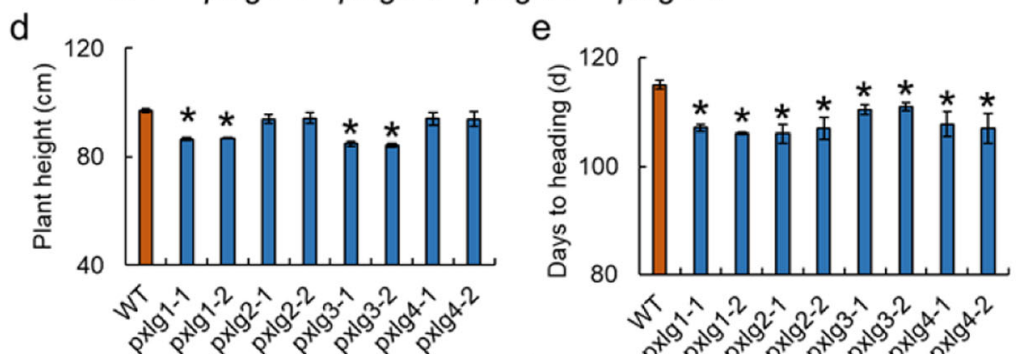

f
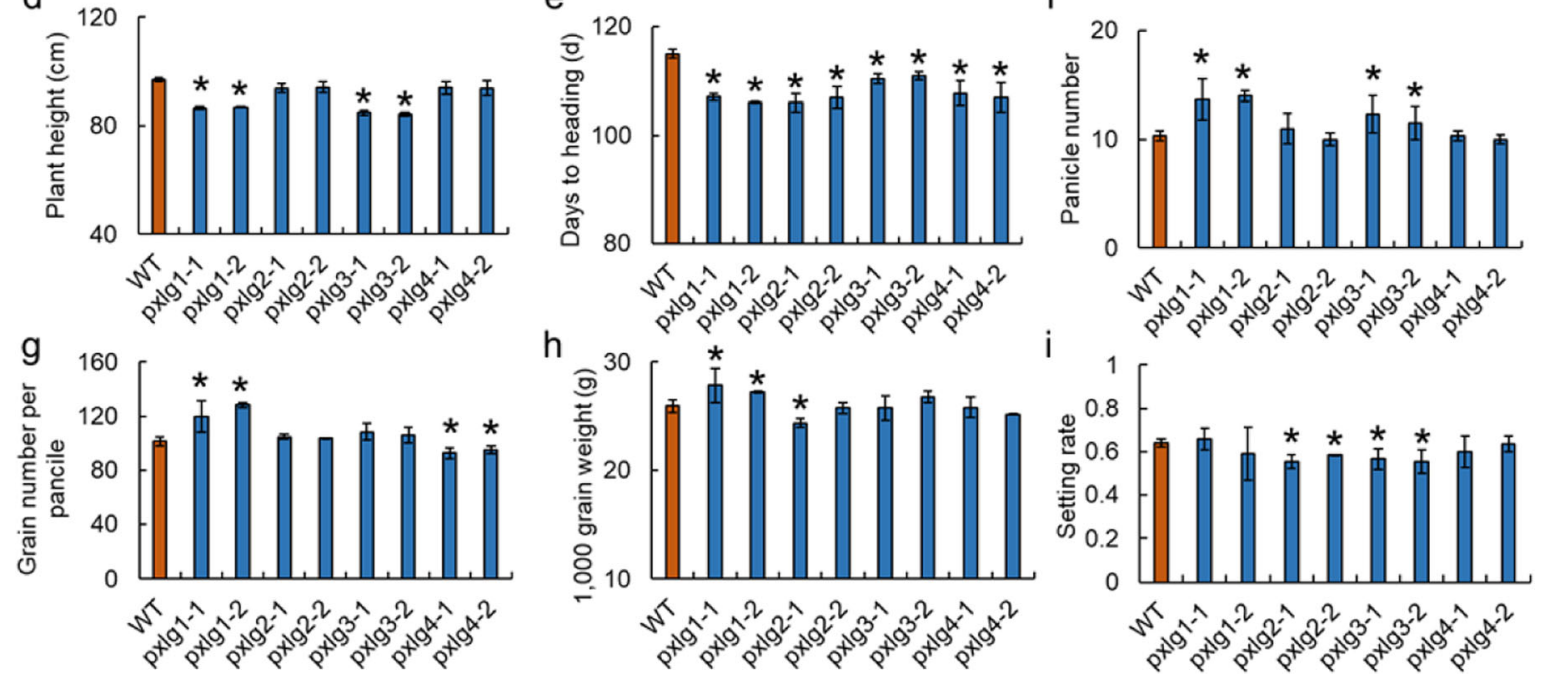

Fig. 5 (See legend on next page.) 
(See figure on previous page.)

Fig. 5 Genetic effects of the putative extra-large Ga protein on plant architecture, panicle size, grain size, and yield components. a The whole plants of the putative extra-large Ga protein mutants. Bar $=10 \mathrm{~cm}$. $\mathbf{b}$ The panicles of the putative extra-large Ga protein mutants. Bar $=1 \mathrm{~cm} . \mathbf{c}$ The grains of the putative extra-large Ga protein mutants. Bar $=1 \mathrm{~cm}$. $\mathbf{d}-\mathbf{i}$ The plant heights, heading times, panicle numbers, grain numbers per panicle, 1000-grain weight, and setting rates of the putative extra-large Ga protein mutants. * indicates significance at the $5 \%$ level

grain number per panicle, the opposite effects might due to the different genetic background, and a complex genetic network might exist in heterotrimeric G protein signaling in rice.

Studies of the extra-large Go protein in Arabidopsis have demonstrated that the heterotrimeric XLG-GBY proteins represent additional signal transduction mechanisms in plant heterotrimeric $\mathrm{G}$ protein signaling $[9-11,44]$.
However, the function of XLGs in the rice genome is unclear. The bioinformatics analysis indicated that there were four putative extra-large Go protein encoding genes (PXLG1-4) in the genome of rice. We generated the mutants of four pxlg1-4 mutants using CRISPR/Cas9. All four pxlg mutants showed an earlier heading phenotype than the WT, and various phenotypic changes in yield components and stress tolerance were observed in the
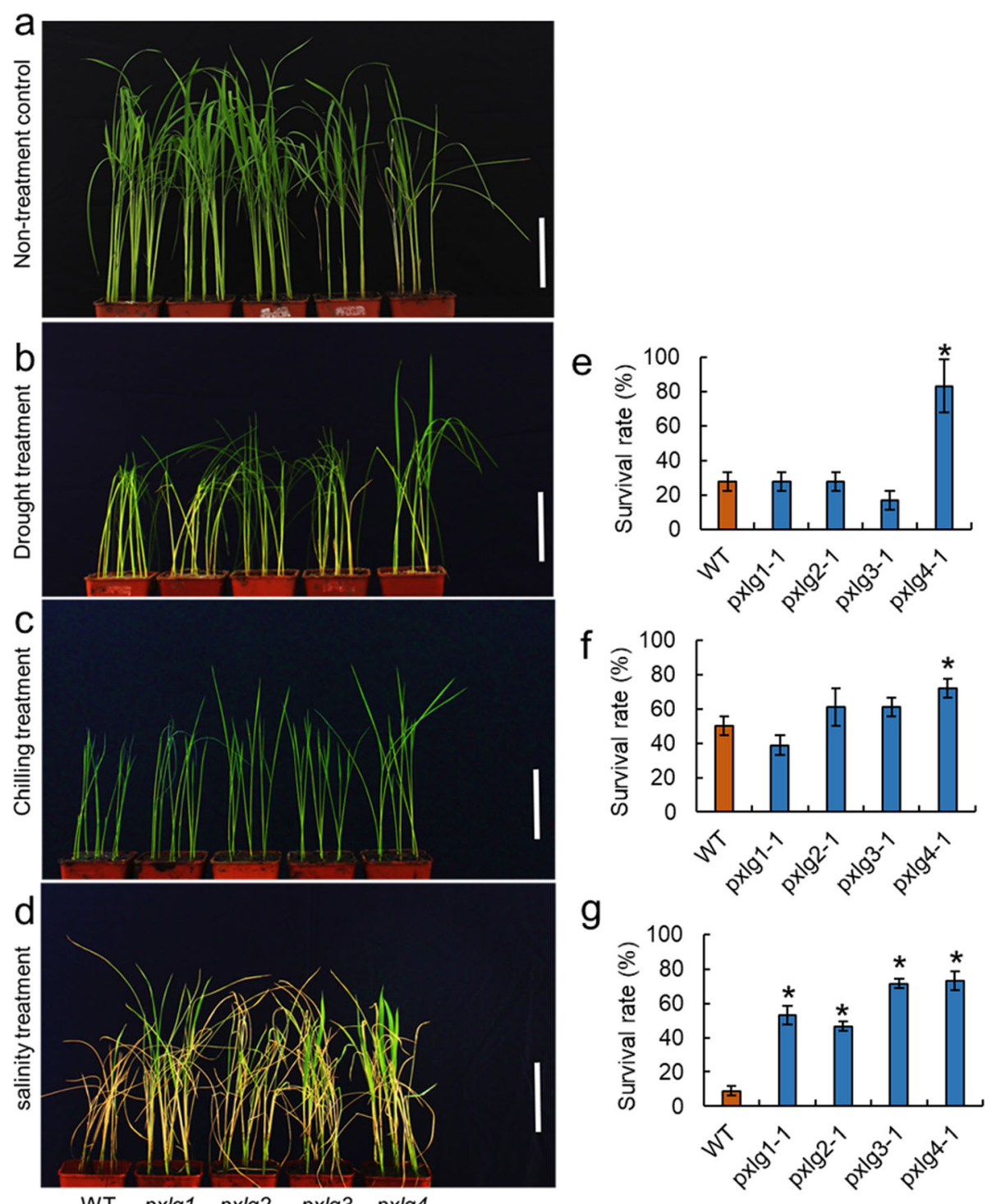

g

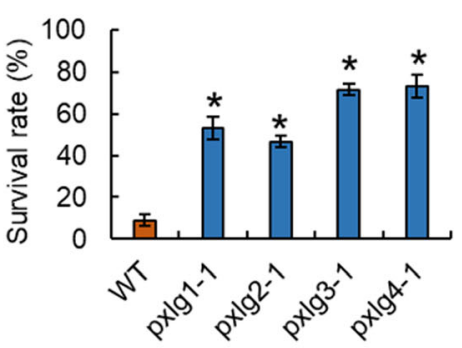

Fig. 6 The stress tolerance of the putative extra-large Ga protein mutants. a The non-treatment control of the WT and putative extra-large Ga protein mutants. b-d Photos of plants treated with drought, chilling, and salinity stress. e- $\mathbf{g}$ The survival rates after drought, chilling, and salinity stress. Bar $=10 \mathrm{~cm}$. * indicates significance at the $5 \%$ level 

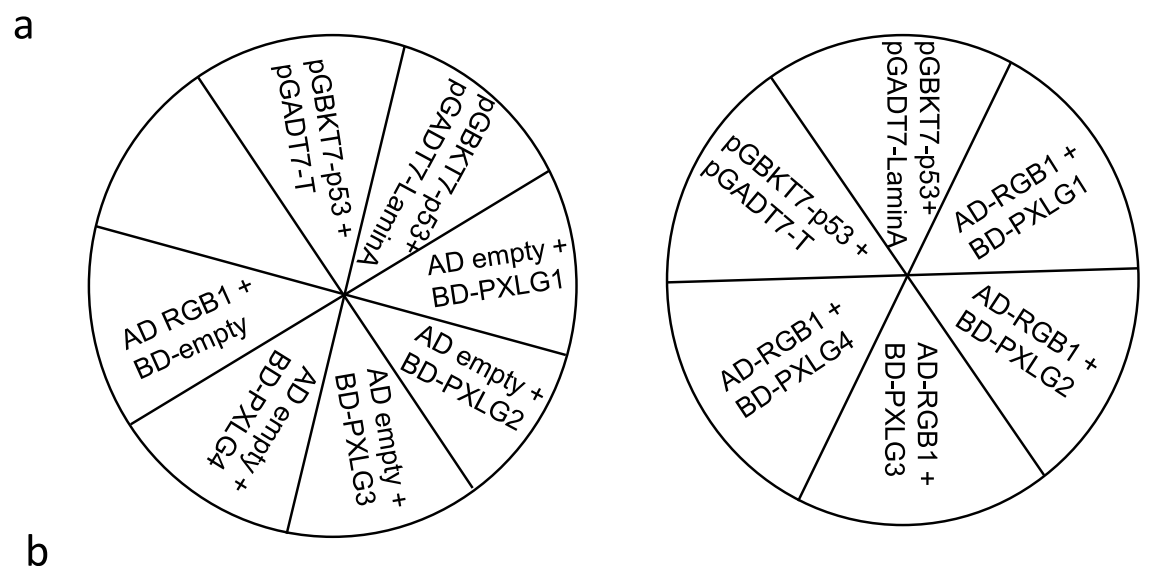

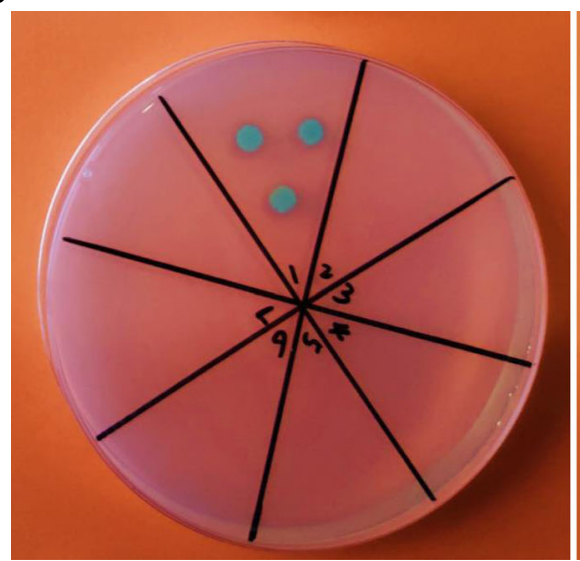

SD/-Trp-Leu-Ade-His/X-a-gal

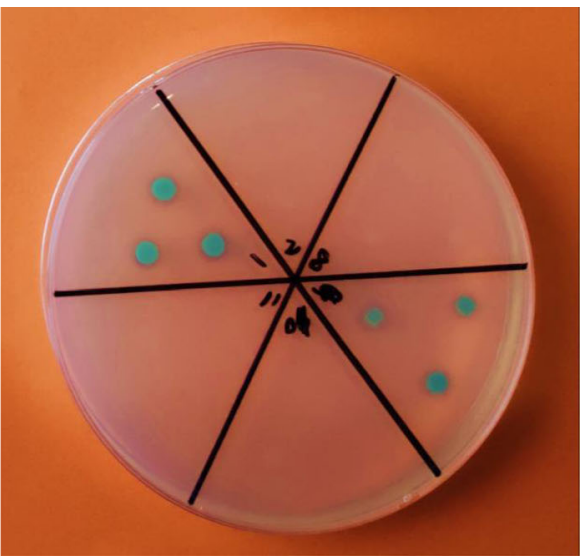

SD/-Trp-Leu-Ade-His/X-a-gal

Fig. 7 Interaction of RGB1 with PXLGs. In the yeast two hybrid assay, RGB1 is used as a prey (AD), and the PXLGs are used as bait (BD) (a) The corresponding positions in the self-activation test and yeast two hybrid assay. $\mathbf{b}$ The result of self-activation test and yeast two hybrid assay. Two plasmids containing either an AD or BD construct were introduced into a yeast strain and transformants were grown on selective medium lacking Leu and Trp. pGBKT7-p53 + pGADT7-T was used as a positive control, and pGBKT7-p53 + pGADT7-LaminA was used as a negative control

comparison between the WT and mutants. As the yeast two hybrid analysis showed that RGB1 could only interact with PXLG2, we expected that the mutant of $p x \lg 2$ could generated obvious agronomic changes compared to other mutants of PXLGs. However, the mutant of pxlg2 showed mediocre phenotypic change among the four mutants of $p x l g s$, whereas the mutant of $p x l g 1$ showed more severe changes in panicle length and grain size, and mutant of pxlg4 showed improved stress tolerance compared to other mutants of PXLGs. These results indicated that PXLG2 might participate in the regulation of yield components and tress tolerance through the direct interaction with RGB1. Nevertheless, the interaction among four PXLGs needs further study.

Yield is the latest addition to the growing list of critical traits modulated by heterotrimeric $\mathrm{G}$ signaling in plants [12]. By combining different $G$ protein variants, the grain length could be decreased by up to $35 \%$ or increased by up to $19 \%$, leading to an over $40 \%$ decrease or a $28 \%$ increase in grain weight [31]. The present study constructed heterotrimeric $G$ protein mutants in an identical genetic background. The effects of the heterotrimeric G protein in the regulation of yield components and stress tolerance were assessed. We found that the gs 3 and dep 1 mutants showed an ideal phenotype regarding both yield components and stress tolerance. The pxlg4 mutant exhibited similar yield components but enhanced stress tolerance compared to the WT. The grain yield per plant of the WT was $17.38 \pm 0.99 \mathrm{~g}$, and those of $p x \lg 1-1$ and $p x \lg 1-2$ were $29.96 \pm 1.59 \mathrm{~g}$ and $28.88 \pm 0.95 \mathrm{~g}$, respectively. Thus, $p x \lg 1$ could improve the grain yield per plant by $69 \%$ under our experimental conditions, indicating that PXLG1 has a potential application in high yield rice breeding. Taken together, the results from the manipulation of $\mathrm{G}$ protein signaling might lead to improvements in yield and stress tolerance in rice and other crop species.

\section{Conclusions}

The present study generated one $\mathrm{G} \alpha$, one $\mathrm{G} \beta$, and five $\mathrm{G} \gamma$ mutants using CRISPR/Cas9 gene-editing technology. The 
bioinformatics analysis showed that there were four putative extra-large $\mathrm{G} \alpha$ protein encoding genes (PXLG1-4) in the genome of rice. The yield components and stress tolerance were surveyed. The results showed that the heterotrimeric $G$ proteins were involved in the regulation of yield components and stress tolerance. The yeast two hybrid assay showed that PXLG2 might interact with RGB1. These findings not only improve our understanding of the repertoire of heterotrimeric $G$ proteins in rice but also contribute to the application of heterotrimeric $\mathrm{G}$ proteins in rice breeding.

\section{Methods}

CRISPR/Cas9 vector construction and plant transformation

The experiment was conducted under the genetic background of the Japanese commercial japonica cultivar Sasanishiki. The seed of Sasanishiki (JP number: 5354) was ordered from the Genebank Project, NARO (Tsukuba, Japan). According to the standard material transfer agreement of Genebank, the seeds from Genebank were available to conduct scientific research and education. In order to perform the CRISPR/Cas9 gene editing, we conducted the vector construction as described in our previous study [45]. We conducted the rice transformation according to previously described method [46]. Genomic DNA was extracted from the mutant plants, and primer pairs flanking the designed target site were used for PCR amplification. The $200-500 \mathrm{bp}$ PCR products were sequenced directly using the Degenerate Sequence Decoding method [21]. The primer used in the present study was listed in additional file 1.

\section{Field experiments}

Field experiments were conducted at the experimental farm of Shenyang Agricultural University, Shenyang, China $\left(\mathrm{N} 41^{\circ}, \mathrm{E} 123^{\circ}\right)$ in 2018. Two independent transgenic lines for each heterotrimeric $G$ protein were prepared except for $r g g 2$, which only had single transgenic line. Seeds of mutants and WT were sown on 24 April, and transplanting (one seedling per hill) was conducted on 23 May. A randomized block design with three replicates was used in the present study. The plot was $5.4 \mathrm{~m}^{2}$ and contained 120 plants with $30 \mathrm{~cm} \times 15 \mathrm{~cm}$ intervals. The cultivation method and field management were as described previously [38]. We harvested the aboveground parts of 24 plants for each transgenic line at the mature stage ( 35 days after the full heading stage). The number of grains per panicle and grain-filling percentage were calculated based on the above data.

\section{Stress tolerance investigation}

The fully filled and uniform rice seeds of the WT and mutants were washed with $70 \%(\mathrm{v} / \mathrm{v})$ ethanol for $30 \mathrm{~s}$ and then washed three times with sterile water. The stress treatment was conducted 3 weeks after sowing. To test chilling tolerance, 27 seedlings per genotype were treated at $2-4{ }^{\circ} \mathrm{C}$ for $72 \mathrm{~h}$. Subsequently, they were moved to a temperature-controlled $\left(30^{\circ} \mathrm{C}\right.$ day $/ 22^{\circ} \mathrm{C}$ night) greenhouse for recovery. For the drought treatment, 27 seedlings per genotype were exposed to dehydration stress in a greenhouse $\left(30^{\circ} \mathrm{C}\right.$ day $/ 22^{\circ} \mathrm{C}$ night) by withholding water for up to $10 \mathrm{~d}$ until variation in the stress response was observed. We then added water for recovery. We compared the salinity tolerance of the WT and homozygous mutant plants in the greenhouse, and the three-week-old plants were treated with fresh groundwater and $0.75 \% \mathrm{NaCl}$ solution $(\mathrm{pH}=7)$, respectively. After 2 weeks of treatment, the plants were treated with fresh groundwater for recovery. The survival rate was determined after 2 weeks of recovery. Each line was replicated three times.

\section{Statistical analyses}

Statistical analyses were performed using SPSS version 13.0 (SPSS, Chicago, IL, USA) and analyzed with Student's $t$ test and two-way analysis of variance (ANOVA). Values represent the mean \pm standard deviation (SD) of three replicates, and significant differences at the 0.05 level are indicated by asterisks or different letters in the figures.

\section{Yeast two-hybrid analysis}

Yeast two-hybrid experiments were performed using the Matchmaker Two-Hybrid System (Clontech). The coding sequences of RGB1, and four PXLGs were amplified using primers listed in additional file 1 . Then we cloned the obtained fragments into PGADT7 and PGBKT7 separately. The detail of yeast two hybrid assay was described in elsewhere [31].

\section{Supplementary information}

Supplementary information accompanies this paper at https://doi.org/10. 1186/s12870-020-2289-6.

Additional file 1. The primer used in present study

Abbreviations

CRISPR: Clustered regularly interspaced short palindromic repeats; PXLG: Putative extra-large G protein; QTL: Quantitative trait loci; SD: Standard deviation; WT: Wild type

\section{Acknowledgments}

Not applicable.

Authors' contributions

Q.X. and Z.X. designed this study and contributed to the original concept of the project; Y.C. and N.J. performed most of the experiments; Q.X. wrote the paper. All authors read and approved the final manuscript.

\section{Funding}

Funding for this work was provided by the National Key R\&D Program of China (2017YFD0100500). The founding body had no role in the design of 
the study and collection, analysis, and interpretation of data and in writing the manuscript.

\section{Availability of data and materials}

The datasets used and/or analysed during the current study are available from the corresponding author on reasonable request.

\section{Ethics approval and consent to participate}

Not applicable.

\section{Consent for publication}

Not applicable.

\section{Competing interests}

The authors declare that they have no competing interests.

\section{Author details}

${ }^{1}$ Rice Research Institute of Shenyang Agricultural University, Shenyang 110866, China. ${ }^{2}$ Shenyang Research and Development Service Center of Modern Agriculture, Shenyang 110866, China.

\section{Received: 10 October 2019 Accepted: 13 February 2020}

\section{Published online: 28 February 2020}

\section{References}

1. Gilman AG. G proteins: transducers of receptor-generated signals. Annu Rev Biochem. 1987;56(1):615-49.

2. Wettschureck N, Offermanns S. Mammalian G proteins and their cell type specific functions. Physiol Rev. 2005;85(4):1159-204

3. Jones AM, Assmann SM. Plants: the latest model system for G-protein research. EMBO Rep. 2004;5(6):572-8.

4. Bisht NC, Jez JM, Pandey S. An elaborate heterotrimeric G-protein family from soybean expands the diversity of plant G-protein networks. New Phytol. 2011;190(1):35-48.

5. Trusov Y, Chakravorty D, Botella JR. Diversity of heterotrimeric G-protein $Y$ subunits in plants. BMC Res Notes. 2012;5(1):608.

6. Ishikawa A, Tsubouchi H, Iwasaki Y, Asahi T. Molecular cloning and characterization of a CDNA for the a subunit of a $\mathrm{G}$ protein from rice. Plant Cell Physiol. 1995;36(2):353-9.

7. Zhang D, Zhou Y, Yin J, Yan X, Lin S, Xu W, Baluska F, Wang Y, Xia Y, Liang $G$, et al. Rice G-protein subunits aPE9-1 and RGB1 play distinct roles in abscisic acid responses and drought adaptation. J Exp Bot. 2015;66(20): 6371-84.

8. Kato C, Mizutani T, Tamaki H, Kumagai H, Kamiya T, Hirobe A, Fujisawa Y, Kato $\mathrm{H}$, Iwasaki $Y$. Characterization of heterotrimeric $\mathrm{G}$ protein complexes in rice plasma membrane. Plant J. 2004:38(2):320-31.

9. Lee Y-RJ, Assmann SM. Arabidopsis thaliana 'extra-large GTP-binding protein'(AtXLG1): a new class of G-protein. Plant Mol Biol. 1999:40(1):55-64.

10. Zhu H, Li G-J, Ding L, Cui X, Berg H, Assmann SM, Xia Y. Arabidopsis extra large $\mathrm{G}$-protein 2 (XLG2) interacts with the $\mathrm{G} \beta$ subunit of heterotrimeric $\mathrm{G}$ protein and functions in disease resistance. Mol Plant. 2009;2(3):513-25.

11. Heo JB, Sung S, Assmann SM. Ca2+-dependent GTPase, extra-large G protein 2 (XLG2), promotes activation of DNA-binding protein related to vernalization 1 (RTV1), leading to activation of floral integrator genes and early flowering in Arabidopsis. J Biol Chem. 2012;287(11):8242-53.

12. Botella JR. Can heterotrimeric $G$ proteins help to feed the world? Trends Plant Sci. 2012;17(10):563-8.

13. Choudhury SR, Bisht NC, Thompson R, Todorov O, Pandey S. Conventional and novel Gy protein families constitute the heterotrimeric G-protein signaling network in soybean. PLoS One. 2011;6(8):e23361.

14. Wolfenstetter S, Chakravorty D, Kula R, Urano D, Trusov Y, Sheahan MB, McCurdy DW, Assmann SM, Jones AM, Botella JR. Evidence for an unusual transmembrane configuration of AGG3, a class C Gy subunit of Arabidopsis. Plant J. 2015;81(3):388-98.

15. Urano D, Miura K, Wu Q, Iwasaki Y, Jackson D, Jones AM. Plant Morphology of Heterotrimeric G protein Mutants. Plant Cell Physiol. 2016;57(3):437-45.

16. Fan C, Yu S, Wang C, Xing Y. A causal C-A mutation in the second exon of GS3 highly associated with rice grain length and validated as a functional marker. Theor Appl Genet. 2009;118(3):465-72.

17. Takano-Kai N, Jiang H, Kubo T, Sweeney M, Matsumoto T, Kanamori H, Padhukasahasram B, Bustamante C, Yoshimura A, Doi K. Evolutionary history of GS3, a gene conferring grain length in rice. Genetics. 2009;182(4): 1323-34.

18. Huang X, Qian Q, Liu Z, Sun H, He S, Luo D, Xia G, Chu C, Li J, Fu X. Natural variation at the DEP1 locus enhances grain yield in rice. Nat Genet. 2009; 41(4):494-7.

19. Sun H, Qian Q, Wu K, Luo J, Wang S, Zhang C, Ma Y, Liu Q, Huang X, Yuan Q. Heterotrimeric $G$ proteins regulate nitrogen-use efficiency in rice. Nat Genet. 2014;46(6):652-6

20. Wang J, Nakazaki T, Chen S, Chen W, Saito H, Tsukiyama T, Okumoto Y, Xu Z, Tanisaka T. Identification and characterization of the erect-pose panicle gene EP conferring high grain yield in rice (Oryza sativa L.). Theor Appl Genet. 2009;119(1):85-91.

21. Ma X, Zhang Q, Zhu Q, Liu W, Chen Y, Qiu R, Wang B, Yang Z, Li H, Lin Y. A robust CRISPR/Cas9 system for convenient, high-efficiency multiplex genome editing in monocot and dicot plants. Mol Plant. 2015:8(8):1274-84.

22. Li M, Li X, Zhou Z, Wu P, Fang M, Pan X, Lin Q, Luo W, Wu G, Li H. Reassessment of the four yield-related genes Gn1a, DEP1, GS3, and IPA1 in Rice using a CRISPR/Cas9 system. Front Plant Sci. 2016;7:377.

23. Shan Q, Wang Y, Li J, Zhang Y, Chen K, Liang Z, Zhang K, Liu J, Xi JJ, Qiu JL. Targeted genome modification of crop plants using a CRISPR-Cas system. Nat Biotechnol. 2013:31(8):686-8.

24. Wu Q, Xu F, Liu L, Char SN, Ding Y, Je Bl, Schmelz E, Yang B, Jackson D. The maize heterotrimeric $\mathrm{G}$ protein beta subunit controls shoot meristem development and immune responses. Proc Natl Acad Sci USA. 2020;117(3): 1799-1805.

25. Ferrero-Serrano A, Assmann SM. The alpha-subunit of the rice heterotrimeric $G$ protein, $R G A 1$, regulates drought tolerance during the vegetative phase in the dwarf rice mutant d1. J Exp Bot. 2016:67(11):3433-43.

26. Ferrero-Serrano A, Su Z, Assmann SM. Illuminating the role of the Galpha heterotrimeric $G$ protein subunit, $R G A 1$, in regulating photoprotection and photoavoidance in rice. Plant Cell Environ. 2018;41(2):451-68.

27. Utsunomiya $Y$, Samejima C, Takayanagi Y, Izawa Y, Yoshida T, Sawada Y, Fujisawa $Y$, Kato $H$, Iwasaki $Y$. Suppression of the rice heterotrimeric $G$ protein $\beta$-subunit gene, RGB1, causes dwarfism and browning of internodes and lamina joint regions. Plant J. 2011; 67(5):907-916.

28. Xu Q, Zhao M, Wu K, Fu X, Liu Q. Emerging insights into Heterotrimeric G protein signaling in plants. J Genet Genomics. 2016;43(8):495-502.

29. Miao J, Yang Z, Zhang D, Wang Y, Xu M, Zhou L, Wang J, Wu S, Yao Y, Du $X$, et al. Mutation of RGG2, which encodes a type $B$ heterotrimeric $G$ protein gamma subunit, increases grain size and yield production in rice. Plant Biotechnol J. 2019;17(3):650-64

30. Mao H, Sun S, Yao J, Wang C, Yu S, Xu C, Li X, Zhang Q. Linking differential domain functions of the GS3 protein to natural variation of grain size in rice. Proc Natl Acad Sci U S A. 2010;107(45):19579-84.

31. Sun S, Wang L, Mao H, Shao L, Li X, Xiao J, Ouyang Y, Zhang Q. A G-protein pathway determines grain size in rice. Nat Commun. 2018;9(1):851.

32. Gao Y, Gu H, Leburu M, Li X, Liang G. The heterotrimeric G protein $\beta$ subunit RGB1 is required for seedling formation in rice. Rice. 2019;12(1):53.

33. Ashikari M, Wu J, Yano M, Sasaki T, Yoshimura A. Rice gibberellin-insensitive dwarf mutant gene dwarf 1 encodes the alpha-subunit of GTP-binding protein. Proc Natl Acad Sci U S A. 1999:96(18):10284-9.

34. Fujisawa Y, Kato T, Ohki S, Ishikawa A, Kitano H, Sasaki T, Asahi T, Iwasaki Y. Suppression of the heterotrimeric $G$ protein causes abnormal morphology, including dwarfism, in rice. Proc Natl Acad Sci U S A. 1999:96(13):7575-80.

35. Jangam AP, Pathak RR, Raghuram N. Microarray analysis of Rice d1 (RGA1) mutant reveals the potential role of $\mathrm{G}$-protein alpha subunit in regulating multiple abiotic stresses such as drought, salinity, heat, and cold. Front Plant Sci. 2016;7:11

36. Ma Y, Dai X, Xu Y, Luo W, Zheng X, Zeng D, Pan Y, Lin X, Liu H, Zhang D. COLD1 confers chilling tolerance in rice. Cell. 2015;160(6):1209-21.

37. Fan C, Xing Y, Mao H, Lu T, Han B, Xu C, Li X, Zhang Q. GS3, a major QTL for grain length and weight and minor QTL for grain width and thickness in rice, encodes a putative transmembrane protein. Theor Appl Genet. 2006: 112(6):1164-71

38. Li X, Wu L, Wang J, Sun J, Xia X, Geng X, Wang X, Xu Z, Xu Q. Genome sequencing of rice subspecies and genetic analysis of recombinant lines reveals regional yield- and quality-associated loci. BMC Biol. 2018;16(1):102.

39. Shen L, Hua Y, Fu Y, Li J, Liu Q, Jiao X, Xin G, Wang J, Wang X, Yan C. Rapid generation of genetic diversity by multiplex CRISPR/Cas9 genome editing in rice. Sci China Life Sci. 2017;60(5):506-15. 
40. Li X, Tao Q, Miao J, Yang Z, Gu M, Liang G, Zhou Y. Evaluation of differential qPE9-1/DEP1 protein domains in rice grain length and weight variation. Rice. 2019;12(1):5.

41. Wang Y, Geng L, Yuan M, Wei J, Jin C, Li M, Yu K, Zhang Y, Jin H, Wang E. Deletion of a target gene in Indica rice via CRISPR/Cas9. Plant Cell Rep. 2017;36(8):1-11.

42. Yi X, Zhang Z, Zeng S, Tian C, Peng J, Li M, Lu Y, Meng Q, Gu M, Yan C. Introgression of qPE9-1 allele, conferring the panicle erectness, leads to the decrease of grain yield per plant in japonica rice (Oryza sativa L.). J Genet Genomics. 2011;38(5):217-23.

43. Zhou Y, Zhu J, Li Z, Yi C, Liu J, Zhang H, Tang S, Gu M, Liang G. Deletion in a quantitative trait gene qPE9-1 associated with panicle erectness improves plant architecture during rice domestication. Genetics. 2009;183(1):315-24.

44. Chakravorty D, Gookin TE, Milner MJ, Yu Y, Assmann SM. Extra-large G proteins expand the repertoire of subunits in Arabidopsis Heterotrimeric $G$ protein signaling. Plant Physiol. 2015;169(1):512-29.

45. Cui Y, Zhu M, Xu Z, Xu Q. Assessment of the effect of ten heading time genes on reproductive transition and yield components in rice using a CRISPR/Cas9 system. Theor Appl Genet. 2019;132(6):1887-96.

46. Nishimura A, Aichi I, Matsuoka M. A protocol for agrobacterium-mediated transformation in rice. Nat Protoc. 2006;1 (6):2796.

\section{Publisher's Note}

Springer Nature remains neutral with regard to jurisdictional claims in published maps and institutional affiliations.

Ready to submit your research? Choose BMC and benefit from:

- fast, convenient online submission

- thorough peer review by experienced researchers in your field

- rapid publication on acceptance

- support for research data, including large and complex data types

- gold Open Access which fosters wider collaboration and increased citations

- maximum visibility for your research: over $100 \mathrm{M}$ website views per year

At $\mathrm{BMC}$, research is always in progress.

Learn more biomedcentral.com/submissions 